\title{
New Approaches to Endocrine Therapy for Breast Cancer
}

\author{
Presented by William J. Gradishar, MD
}

\begin{abstract}
The management of advanced hormone receptor-positive disease has evolved with the emergence of CDK4/6 inhibitors. Improvements in progression-free survival of approximately 10 months were noted in pivotal trials of palbociclib. Strong efficacy was also seen with ribociclib, which was recently approved by the FDA. In the adjuvant treatment setting of hormone receptor-positive disease, an important issue for consideration is the duration of endocrine therapy.
\end{abstract}

J Natl Compr Canc Netw 2017;15(5.5):679-681

\section{New Approaches to Endocrine Therapy}

Optimizing the treatment of estrogen receptor (ER)positive breast cancer depends on overcoming resistance to endocrine agents. This tall effort has met with some success with the availability of targeted agents that inhibit cyclin-dependent kinases 4 and 6 (CDK4/6), according to William J. Gradishar, MD, Chair of the NCCN Breast Cancer Panel and Betsy Bramsen Professor of Breast Oncology, Feinberg School of Medicine, Northwestern University, and Director, Maggie Daley Center for Women's Cancer Care, Robert H. Lurie Comprehensive Cancer Center.

Dr. Gradishar focused on the use of targeted agents as additions to endocrine therapy for metastatic breast cancer and the issue of optimal treatment duration of adjuvant endocrine therapy for early-stage breast cancer. Because these have been key topics of panel discussion for several years, the revisions to this year's NCCN Clinical Practice Guidelines in Oncology (NCCN Guidelines) for Breast Cancer are more "nuanced" than substantial, he said.

Presented by William J. Gradishar, MD, Maggie Daley Center for Women's Cancer Care, Breast Medical Oncology, Robert H. Lurie Comprehensive Cancer Center of Northwestern University, Chicago, Illinois.

Dr. Gradishar has disclosed he has no financial interests, arrangements, affiliations, or commercial interests with the manufacturers of any products discussed in this article or their competitors.

Correspondence: William J. Gradishar, MD, Breast Medical Oncology, Robert H. Lurie Comprehensive Cancer Center of Northwestern

University, 676 North St. Clair Street, Suite 850, Chicago, IL 60611.

E-mail: w-gradishar@northwestern.edu

\section{Overcoming Resistance Is Critical}

"A current focus of clinical research is determining how to overcome the resistance to endocrine therapy that ultimately occurs in metastatic ER-positive breast cancer," Dr. Gradishar said. "We are starting to understand that specific signaling pathways may be responsible."

The NCCN Guidelines have been incorporating "partnering strategies," which involve the addition of targeted agents to endocrine therapy in an effort to combat resistance. To this end, the mTOR inhibitor everolimus was FDA-approved in 2012, the CDK4/6 inhibitor palbociclib entered the armamentarium in 2015, and in 2017 another CDK4/6 inhibitor, ribociclib, earned approval. Additionally, abemaciclib is in late-stage development.

\section{Enthusiasm Builds for CDK4/6 Inhibitors}

"The strategy for overcoming resistance that has gained the most attention in the past few years is the recognition that in breast cancer, as well as in other cancers, there are a variety of mitogens that can drive the cancer cell cycle. In breast cancer, one of these is cyclin D," he said. Cyclin D interacts with cyclin D kinase, leading to a cascade of events that cause cell proliferation.

Enthusiasm for CDK4/6 inhibitors was triggered by results from the open-label, first-line, phase II PALOMA-1 trial, which demonstrated an absolute 10-month improvement in progression-free survival (PFS) when palbociclib was added to letrozole (hazard ratio [HR], 0.49; $P=.0004) .{ }^{1}$ These findings were confirmed by 
the larger phase III PALOMA-2 trial, in which the combination produced $>10$-month improvement in median PFS (24.8 vs 14.5 months; HR, 0.58; $P<.000001){ }^{2}$

"It was remarkable that the results of PALOMA-2 were superimposable on PALOMA-1," Dr. Gradishar commented. "Clearly, this was not just a signal but pretty definitive evidence of improvement in clinical outcomes across the board with the addition of palbociclib."

PALOMA-3 tested palbociclib combined with fulvestrant in patients with prior aromatase inhibitor (AI) therapy, "reflecting what we may do in practice when a patient progresses," he added. The combination doubled the duration of PFS, from 4.6 to 9.6 months. ${ }^{3}$ Together, the 3 pivotal trials with palbociclib confirmed a consistent absolute improvement in median PFS of approximately 10 months versus endocrine therapy alone (Table 1).

Ribociclib similarly extended PFS when given with letrozole in the first-line phase III MONALEESA-2 trial. ${ }^{4}$ At 18 months, PFS was $63.0 \%$ in the ribociclib plus letrozole arm versus $42.2 \%$ in those treated with letrozole alone ( $\left.\mathrm{HR}, 0.56 ; P=3.29 \times 10^{-6}\right)$. Median PFS was not reached with the combination versus 16.4 months with letrozole.

Use of palbociclib in conjunction with either letrozole or fulvestrant for recurrent or stage IV ERpositive and HER2-negative disease is a category 1 recommendation in the NCCN Guidelines. ${ }^{5}$ Ribociclib was only recently approved, so it had not yet been incorporated at the time, but the panel has since included ribociclib in the 2.2017 version of the NCCN Guidelines.

A third CDK4/6 inhibitor, abemaciclib, is being evaluated in a number of ongoing trials. In the MONARCH 1 trial of single agent abemaciclib, responses were seen in $19.7 \%$ of patients who had been heavily pretreated. ${ }^{6}$ The drug is being combined with fulvestrant in MONARCH 2 and with anastrozole or letrozole in MONARCH 3.

\section{Same Class, Different Drugs}

The various CDK4/6 inhibitors "should not be assumed to be exactly the same-clinically, pharmacodynamically, or kinetically," Dr. Gradishar said. "We believe these drugs are not identical, either in terms of efficacy or side effects. We should learn more about

\begin{tabular}{|c|c|c|c|}
\hline & $\begin{array}{c}1003 \\
\text { (PALOMA-1) }\end{array}$ & $\begin{array}{c}1008 \\
\text { (PALOMA -2) }\end{array}$ & $\begin{array}{c}1023 \\
\text { (PALOMA-3) }\end{array}$ \\
\hline Design & $\begin{array}{l}\text { Phase II; open } \\
\text { label }\end{array}$ & $\begin{array}{l}\text { Phase III; placebo } \\
\text { control }\end{array}$ & $\begin{array}{l}\text { Phase III; placebo } \\
\text { control }\end{array}$ \\
\hline $\begin{array}{l}\text { Endocrine } \\
\text { partner }\end{array}$ & Letrozole & Letrozole & Fulvestrant \\
\hline $\begin{array}{l}\text { Patients in } \\
\text { study, } \mathrm{n}\end{array}$ & 165 & 666 & 521 \\
\hline \multicolumn{4}{|c|}{ Efficacy (palbociclib vs control arm) } \\
\hline \multicolumn{4}{|c|}{ Primary end point: PFS } \\
\hline $\mathrm{HR}$ & 0.49 & 0.58 & 0.46 \\
\hline $\begin{array}{l}\text { Median PFS, } \\
\text { mo }\end{array}$ & $\begin{array}{l}20.2 \text { vs } 10.2 \\
(\uparrow 10 \mathrm{mo})\end{array}$ & $\begin{array}{l}24.8 \text { vs } 14.5 \\
(\uparrow 10.3 \mathrm{mo})\end{array}$ & 9.6 vs 4.6 \\
\hline \multicolumn{4}{|c|}{ Secondary end points, $\%$} \\
\hline $\begin{array}{l}\text { ORR (ITT, } \\
\text { measurable } \\
\text { disease) }\end{array}$ & $\begin{array}{l}43 \text { vs } 33 \\
55 \text { vs } 39\end{array}$ & $\begin{array}{l}42 \text { vs } 35 \\
55 \text { vs } 44\end{array}$ & $\begin{array}{l}19 \text { vs } 9 \\
25 \text { vs } 11\end{array}$ \\
\hline CBR (ITT) & 81 vs 58 & 85 vs 70 & 67 vs 40 \\
\hline
\end{tabular}

Abbreviations: CBR, clinical benefit response; HR, hazard ratio; ITT, intent-totreat; ORR, overall response rate; PFS, progression-free survival.

Data from Finn RS, et al. Lancet Oncol 2015;16:25-35; and Cristofanilli M, et al. Data from Lancet Oncol 2016;17:425-439.

their distinguishing features as we see more data from the pivotal trials."

The main toxicity with palbociclib and ribociclib appears to be hematologic, whereas with abemaciclib, gastrointestinal toxicity predominates. It is necessary to monitor WBC counts in patients receiving palbociclib and ribociclib, but those who develop neutropenia "generally don't feel the effects" and febrile neutropenia is uncommon, he indicated.

"As we move forward," he added, clinicians can expect "the coming of the CDK4/6 wars," and efforts by the manufacturers to make distinctions among these drugs.

\section{Everolimus-Containing Regimen Now Follows the CDK4/6 Inhibitor}

The robust activity of the CDK4/6 inhibitors has essentially relegated the mTOR inhibitor, everolimus, to a later line of therapy. "Everolimus in combination with exemestane is in the guidelines, but considered mostly after the patient has had a CDK4/6 inhibitor," Dr. Gradishar explained.

The FDA approved everolimus in combination with exemestane based on the BOLERO-2 trial, in which median PFS was 7.8 months with everolimus plus exemestane versus 3.2 months with exemestane alone (HR, 0.45; P<.0001). ${ }^{7}$ 


\section{Unanswered Questions With These Additional Agents}

With both the CDK4/6 inhibitors and everolimus, there is a need to determine which patients are most likely to benefit from combination therapy and who will have an exceptional response to endocrine therapy alone. "Despite our efforts, we just don't have this information yet," Dr. Gradishar said. "Biomarker development is critical."

Another challenge is to determine how best to sequence the CDK4/6 inhibitors and how to target other signaling pathways implicated in resistance. Of particular interest is the $\mathrm{PI} 3 \mathrm{~K} / \mathrm{Akt} / \mathrm{mTOR}$ pathway, because $\mathrm{PI} 3$ kinase is mutated in many patients with luminal A breast cancer. Dozens of drugs targeting this pathway are in development.

\section{Is There a Place for Extended Endocrine Therapy in the Adjuvant Setting?}

The NCCN Guidelines for Breast Cancer were updated to indicate that women who are postmenopausal at diagnosis and received an AI for 5 years "can consider an AI for an additional 5 years." This includes women who received tamoxifen for 5 years and wish to extend endocrine therapy to 10 years' total duration.

According to Dr. Gradishar, one can "make the case" for extended treatment based on the observation of very late recurrences of ER-positive disease. "Even out to 20 years, you see a progressive increase in recurrence rates," he noted. Pan et $\mathrm{al}^{8}$ reported that, at year 20, the risk for recurrence ranged from $14 \%$ in the lowest-risk group to $47 \%$ in the highest-risk group. "This begs the question of whether continued therapy beyond that 5 years is prudent for some patients," Dr. Gradishar said.

Results from the ATLAS and ATOM trials suggest that extended endocrine therapy exerts a protective effect on mortality only after 10 years, ${ }^{9}$ and a number of trials have consistently shown a modest $(3 \%-5 \%)$ benefit for disease-free survival but no effect on overall survival. In the recently reported NSABP B-42, ${ }^{10}$ DATA, ${ }^{11}$ and IDEAL ${ }^{12}$ studies, no statistically significant difference in disease-free survival was seen with 5 additional years of an AI after initial tamoxifen or AI therapy.

The benefits versus risks of extended adjuvant endocrine therapy must be carefully evaluated and discussed with patients in the decision-making process. Extended duration of endocrine therapy reduces risk of recurrence; however, it does not significantly prolong overall survival. "Also, with longer duration of treatment, the side effects known to us accumulate. So using longer duration of therapy for every patient is incorrect," Dr. Gradishar concluded. "Someday, with gene profiling, we may be able to define which patients will benefit from longer durations."

\section{References}

1. Finn RS, Crown JP, Lang I, et al. The cyclin-dependent kinase $4 / 6$ inhibitor palbociclib in combination with letrozole versus letrozole alone as firstline treatment of oestrogen receptor-positive, HER2-negative, advanced breast cancer (PALOMA-1/TRIO-18): a randomised phase 2 study. Lancet Oncol 2015;16:25-35

2. Finn RS, Martin M, Rugo HS, et al. PALOMA-2: primary results from a phase III trial of palbociclib with letrozole compared with letrozole alone in postmenopausal women with ER+/HER2- advanced breast cancer [abstract]. J Clin Oncol 2016;34(Suppl):Abstract 507.

3. Turner NC, Ro J, Andre F, et al. Palbociclib in hormone-receptor-positive advanced breast cancer. N Engl J Med 2015;373:209-219.

4. Hortobagyi GN, Stemmer SM, Burris HA, et al. Ribociclib as firstline therapy for HR-positive, advanced breast cancer. N Engl J Med 2016;375:1738-1748.

5. Gradishar WJ, Anderson BO, Balassanian R, et al. NCCN Clinical Practice Guidelines in Oncology: Breast Cancer, Version 1.2017. Accessed April 5, 2017. To view the most recent version of these guidelines, visit NCCN.org.

6. Dickler MN, Tolaney SM, Rugo HS, et al. MONARCH1: results from a phase II study of abemaciclib, a CDK4 and CDK6 inhibitor, as monotherapy, in patients with $\mathrm{HR}+/ \mathrm{HER} 2$ - breast cancer, after chemotherapy for advanced disease [abstract]. J Clin Oncol 2016;34(Suppl):Abstract 510.

7. Hortobagyi GN, Piccart-Gebhart MJ, Rugo HS, et al. Correlation of molecular alterations with efficacy of everolimus in hormone receptor- positive, HRE2-negative advanced breast cancer: results of BOLERO-2 [abstract]. J Clin Oncol 2013;31(Suppl):Abstract LBA509.

8. Pan H, Gray RG, Davies C, et al. Predictors of recurrence during years 5-14 in 46,138 women with ER+ breast cancer allocated 5 years only of endocrine therapy (ET) [abstract]. J Clin Oncol 2016;34(Suppl):Abstract 505.

9. Gray RG, Rea D, Handley K, et al. aTTom: long-term effects of continuing adjuvant tamoxifen to 10 years versus stopping at 5 years in 6,953 women with early breast cancer [abstract]. J Clin Oncol 2013;31(Suppl):Abstract 5 .

10. Mamounas EP, Bandos H, Lembersky BC, et al. A randomized, doubleblinded, placebo-controlled clinical trial of extended adjuvant endocrine therapy with letrozole in postmenopausal women with hormone-receptorpositive breast cancer who have completed previous adjuvant treatment with an aromatase inhibitor: results from NRG Oncology/NSABP B-42 [abstract]. Presented at the 2016 San Antonio Breast Cancer Symposium; December 6-10, 2016; San Antonio, Texas. Abstract S1-05.

11. Tjan-Heijnen VC, Van Hellemond IE, Peer PG, et al. First results from the multicenter phase III DATA study comparing 3 versus 6 years of anastrozole after 2-3 years of tamoxifen in postmenopausal women with hormone receptor-positive early breast cancer [abstract]. Presented at the San Antonio Breast Cancer Symposium; December 6-10, 2016; San Antonio, Texas. Abstract S1-03.

12. Blok EJ, van de Velde CJ, Meershoek-Klein Kranenbarg EM, et al. Optimal duration of extended letrozole treatment after 5 years of adjuvant endocrine therapy; results of the randomized phase III IDEAL trial (BOOG 2006-05) [abstract]. Presented at the 2016 San Antonio Breast Cancer Symposium; December 6-10, 2016; San Antonio, Texas. Abstract S1-04. 